\title{
Hierarchical Porous Carbon Microspheres Derived from Biomass-Corncob as Ultra-High Performance Supercapacitor Electrode
}

\author{
Lili Wang ${ }^{l}$, Yanting Li ${ }^{1}$, Kunlong Yang ${ }^{1}$, Wenqi Lu ${ }^{l}$, Jianguo Yu ${ }^{l}$, Jian Gao ${ }^{1}$, Gang Liao , \\ Yuning $Q u^{1, *}$, Xiaofeng Wang ${ }^{2}$, Xifei $\mathrm{Li}^{3}$, Zhen Yin ${ }^{1, *}$ \\ ${ }^{1}$ State Key Laboratory of Separation Membranes and Membrane Processes, School of Environment \\ and Chemical Engineering, Tianjin Polytechnic University, 399 Binshui West Road, Tianjin 300387, \\ P. R. China \\ ${ }^{2}$ State Key Laboratory of Inorganic Synthesis and Preparative Chemistry, College of Chemistry, Jilin \\ University, Changchun 130012, P. R. China \\ ${ }^{3}$ Tianjin International Joint Research Centre of Surface Technology for Energy Storage Materials, \\ College of Physics and Materials Science, Tianjin Normal University, Tianjin 300387, P. R. China \\ *E-mail: qu_yuning0323@163.com, yinzhen@tjpu.edu.cn
}

doi: $10.20964 / 2017.06 .16$

Received: 9 March 2017 / Accepted: 28 March 2017 / Published: 12 May 2017

The hierarchical porous carbon microspheres (HPCS) were obtained using corncob as precursor via a facile and cost-effective approach. The porous carbon microspheres exhibited regular spherical morphology, hierarchical porous, localized graphitization structure and the oxygen-containing functional groups on the surface of carbon spheres. The pore size and specific surface area could be tuned by the amount of $\mathrm{KOH}$ during the activation process. The porous carbon microspheres displayed maximum specific capacitance of $384.5 \mathrm{~F} / \mathrm{g}$ at scan rate of $5 \mathrm{mV} / \mathrm{s}$ and ultra-high rate capacitance of $137.3 \mathrm{~F} / \mathrm{g}$ at the current density of $100 \mathrm{~A} / \mathrm{g}$. The high capacitance retention of the porous carbon microspheres (over 97\%, even with 5000 charge/discharge cycles) demonstrated its superior cycling stability. Moreover, high power density $(62.9 \mathrm{~kW} / \mathrm{kg})$ and energy density $(33.4 \mathrm{Wh} / \mathrm{kg})$ could be achieved at $120 \mathrm{~A} / \mathrm{g}$. Hence, the ultrahigh specific capacitance and exceptional cyclic stability of the porous carbon microspheres indicate its significant potential application in the field of energy storage.

Keywords: Biomass, Carbon microspheres, Hierarchical pore, Supercapacitors

\section{$\underline{\text { FULL TEXT }}$}

(C) 2017 The Authors. Published by ESG (www.electrochemsci.org). This article is an open access article distributed under the terms and conditions of the Creative Commons Attribution license (http://creativecommons.org/licenses/by/4.0/). 